\title{
Temporal-Spatial Distribution Characteristics of Inhalable Particulate Matter and the Impacts of Meteorological Factors in Northern Cities of China
}

\author{
Cheng Huibo ${ }^{1,2,}{ }^{*}$,Wang Naiang ${ }^{1}, \mathrm{He} \mathrm{Li}^{2}$, Li Xiaohong ${ }^{2}$, Gao Xiang ${ }^{1}$, Wang Zhen ${ }^{2}$, Wangting ${ }^{2}$ and \\ Yu Tengfei ${ }^{3}$
}

${ }^{1}$ College of Earth and Environmental Sciences Lanzhou University, Lanzhou 7300000, P.R. China; ${ }^{2}$ Gansu Province Environmental Monitoring Center, Lanzhou 7300000, P.R. China; ${ }^{3}$ Cold and Arid Regions Environmental Engineering Research Institute, Chinese Academy of Sciences, Lanzhou 7300000, P.R. China

\begin{abstract}
Inhalable particulate matter seriously affects ambient air quality. To analyze temporal-spatial distribution characteristics of PM10 pollution and the impacts of meteorological factors in China since 2000, using statistical methods and GIS, monitoring data of PM10 during 2000-2013 in China were analyzed. It was found that annual mean of PM10 in northern cities of China basically presented declining tendency since 2000. PM10 concentration in northern cities of China had obvious seasonal change characteristics, and monthly average PM10 concentration which was higher during November-December and January-April and had double-peak characteristics. PM10 pollution in northern cities of China was eased largely, and heavily polluted area significantly reduced. The overall tendency changed from the concentrated contiguous distribution into sporadic zonal and punctiform distribution. Meteorological factors had important impacts on PM10 in northern cities of China. PM10 concentration and wind velocity presented negative correlation when wind velocity $<6 \mathrm{~m} / \mathrm{s}$ and positive correlation when wind velocity $\geq 6 \mathrm{~m} / \mathrm{s}$. Relative humidity was an important factor affecting inhalable particulate matter pollution in northern cities of China in winter, and high-humidity air was easy to cause heavier particulate matter pollution. Temperature and atmospheric pressure had no obvious impact on inhalable particulate matter pollution in northern cities of China.
\end{abstract}

Keywords: Inhalable particulate matter, meteorological factors, PM10, temporal-spatial distribution.

\section{INTRODUCTION}

With the rapid development of urbanization and industrialization, urban ambient air quality is subject to varying degrees of pollution, and has become an important challenge threatening healthy living of urban residents and sustainable development of urban society [1-4]. Pollutants affecting urban ambient air quality mainly include sulfur dioxide, nitrogen oxides, carbon monoxide, ozone and particulate matter. In recent global environmental change researches, it has been proved that the concentration of particulate matter in the air was an important factor and indicator reflecting atmospheric pollution [5-8]. Via the transportation of winter wind and westerly, atmospheric particulate matters generated in northwest inland of China not only fell in Loess Plateau, but also flied to eastern China, Japan and North Pacific, and even to North America and Greenland by westerly, or to Arctic region by radial circulation [9-12]. As major component of atmospheric particulate, PM10 could enter human respiratory system, which had great harm on human health $[13,14]$. Relevant researches showed that the concentration of inhalable particulate matter presented strong positive correlation relationship with human respiratory diseases and cardiovascular diseases. In addition, inhalable particulate matter also had important influences on atmospheric visibility and global climate change. Chinese particulate matter monitoring experienced the development process of dust fall-total suspended particles (TSP) - inhalable particulate matter (PM10) -fine particulate matter (PM2.5). Started from 2000, some cities of China started to monitor PM10, and most cities still monitored TSP. In 2002, the cities monitoring PM10 and TSP respectively accounted for $1 / 2$. To 2006 , the cities of local-level and above basically realized PM10 monitoring. PM10 was primary pollutant affecting China ambient air quality, and it had important significance to implement relevant researches about PM10. Using monitoring data in some representative cities of northern China during 2000-2013, temporal-spatial distribution pattern of PM10 pollution and the impacts of meteorological factors were analyzed. We aimed to provide scientific basis for prevention and control of PM10 pollution in China.

\section{DATA SOURCE}

The research data were from each monitoring station of national sand and dust weather affecting urban ambient air quality. Layout of each site comprehensively considered natural geographical location, climatic condition and industrial pollution level of the city, and could better represent 
environmental quality of the region. As shown in Fig. (1), there were 68 monitoring stations, and the used monitoring instrument at each station was TEOM 1400A PM10 automatic monitoring instrument of USA ThermoFisher Company. In addition, USA Belfort Model 6000 visibility meter and USA WS313E1T505103V five meteorological parameters instrument were used to monitor visibility, wind direction, wind velocity, temperature, humidity and atmospheric pressure. The research data were from 2000 to 2013. North China has vast territory and complex terrain. According to terrain and local climate characteristics, North China is divided into four regions: northeast district (east Inner Mongolia, Liaoning, Jilin, Heilongjiang), northern district (central Inner Mongolia, Tianjin, Beijing, Shanxi, Henan, Shandong, Hebei), eastern area of northwest district (west Inner Mongolia, Qinghai, Ningxia, Gansu, Shaanxi) and western area of northwest district (Xinjiang).

\section{RESULT AND DISCUSSION}

\subsection{Temporal Distribution Characteristics of PM10 in Northern Cities of China}

Relevant research data showed that annual average PM10 concentration in major cities of China was $0.139 \mathrm{mg} / \mathrm{m}^{3}$ in $2000,0.131 \mathrm{mg} / \mathrm{m}^{3}$ in 2002 and $0.083 \mathrm{mg} / \mathrm{m}^{3}$ in 2005 . For China's northern cities, due to the impacts of natural geographical condition, climatic condition and industrial pollution, annual average PM10 concentrations in 2000, 2002 and
2005 were higher than $0.139,0.131$ and $0.083 \mathrm{mg} / \mathrm{m}^{3}$ respectively. The research showed that annual average PM10 concentration in China's northern cities was $0.078 \mathrm{mg} / \mathrm{m}^{3}$ in $2011,0.074 \mathrm{mg} / \mathrm{m}^{3}$ in 2012 and $0.071 \mathrm{mg} / \mathrm{m}^{3}$ in 2013 . It was clear that annual average PM10 concentration in northern cities of China presented declining tendency since 2000.

According to change situation of monthly average PM10 concentration in China's northern cities during 2000-2013 (Fig. 2), it was clear that PM10 concentration in China's northern cities had obvious seasonal change characteristics. Monthly average PM10 concentration was higher during November-December and January-April and had doublepeak characteristics. The maximum appeared in March, and the second highest value appeared in December. Monthly average concentration of particulate matter was relatively lower in summer and autumn. It was because that temperate continental climate and temperate monsoon climate were dominant in China's northern cities, and spring when sand and dust weather frequently occurred had important impact on PM10 concentration. It was cold in winter, and coal-fired heating could emit a large amount of particulate matters, causing that winter PM10 concentration in China's northern cities was higher.

Taking 2013 as an example, hourly average PM10 concentration in China's northern cities was shown as Fig. (3). It was clear that hourly average PM10 concentration in China's northern cities in 2013 was overall lower than $1.0 \mathrm{mg} / \mathrm{m} 3$,

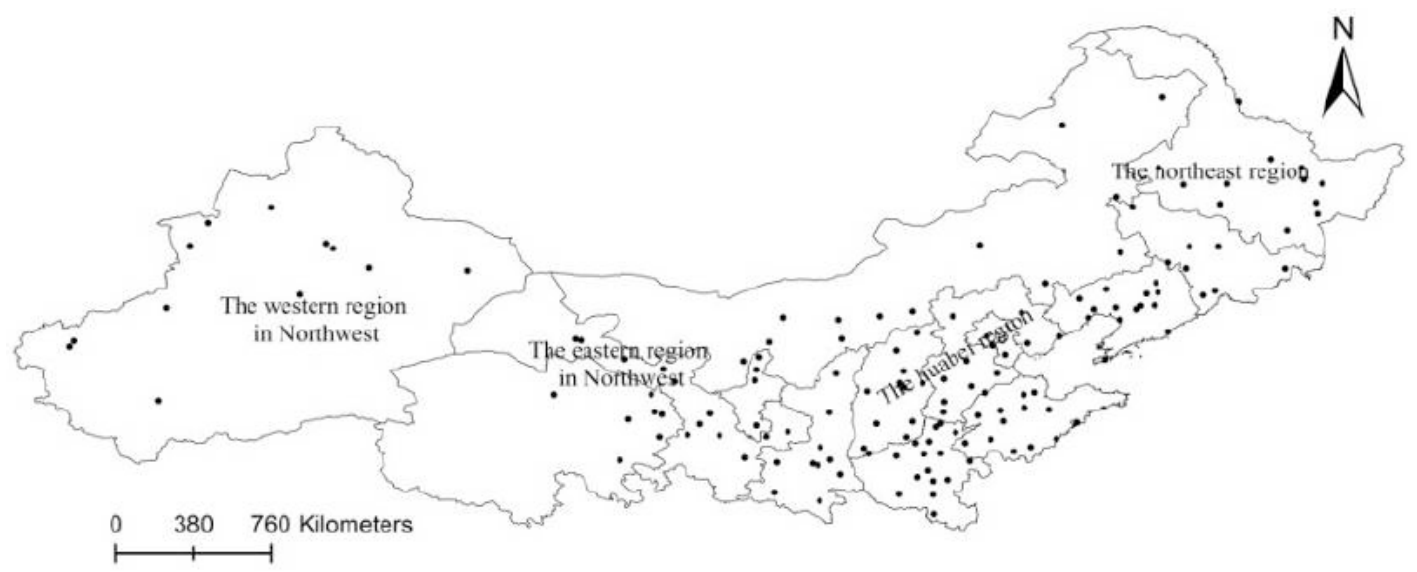

Fig. (1). Regional division chart of North China.

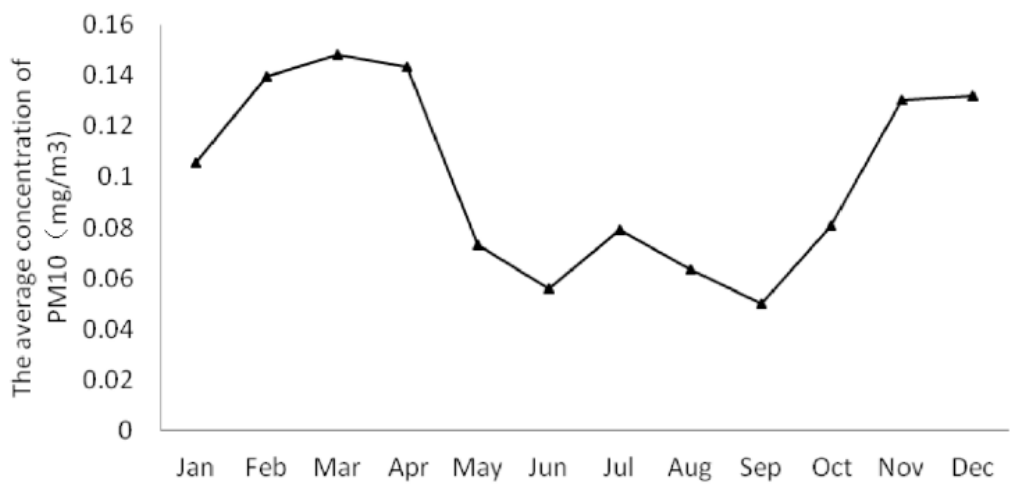

Fig. (2). Monthly average $\mathrm{PM}_{10}$ concentration in China's northern cities during 2000-2013. 


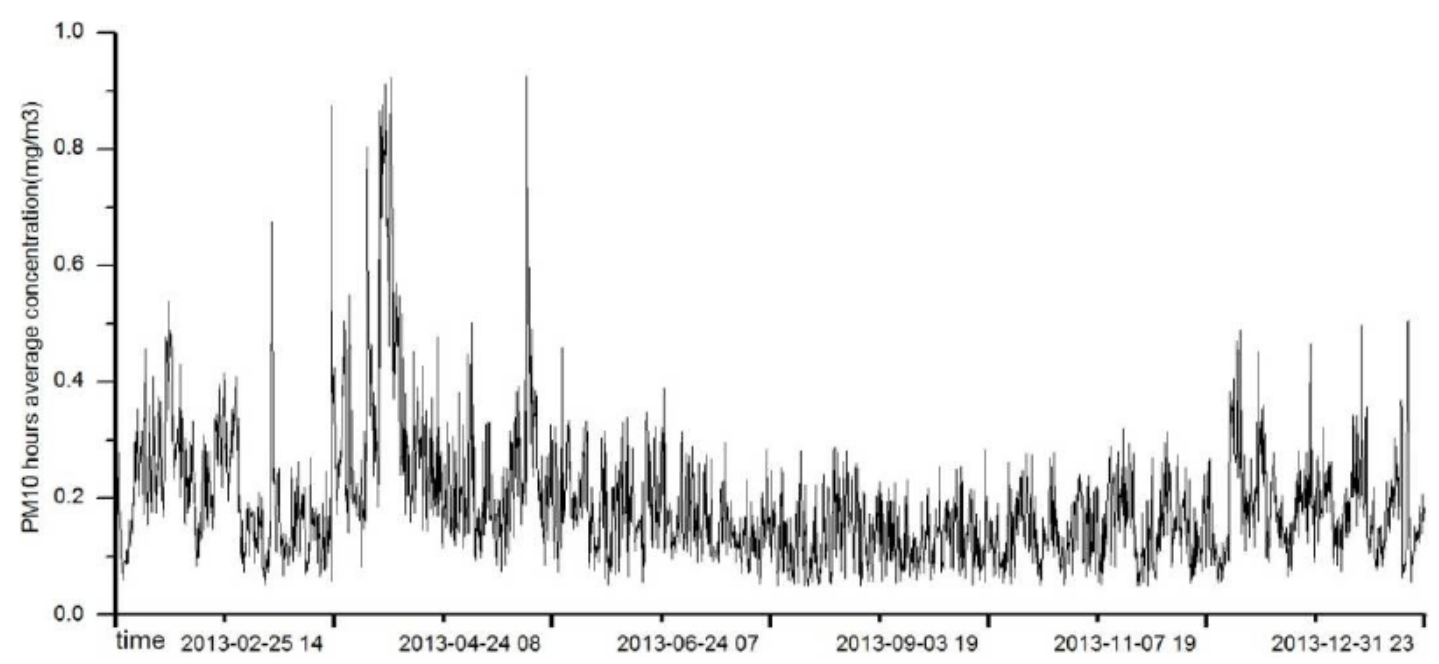

Fig. (3). Hourly average $\mathrm{PM}_{10}$ concentration in China's northern cities in 2013.

and its peak mainly occurred during February-April, showing that the impact of sand and dust weather on PM10 concentration in China's northern cities was greater than that of coal-fired heating. Hourly average PM10 concentration in China's northern cities during May-October was lower than $0.4 \mathrm{mg} / \mathrm{m} 3$. During the period, ambient air quality in China's northern cities was better.

\subsection{Spatial Distribution Characteristics of PM10 in China's Northern Cities}

Spatial interpolation of annual average PM10 value in China's northern major cities in 2000, 2006 and 2013 was conducted in ArcGIS, and spatial distribution pattern of PM10 pollution in China's northern cities in corresponding years was obtained (Fig. 4).

During 2000-2013, PM10 pollution in major cities of northern China was eased at certain degree, and heavily polluted area significantly decreased. The overall trend changed from the concentrated contiguous distribution into sporadic zonal and punctiform distribution. But seen from regional distribution, spatial distribution of PM10 pollution did not change significantly. PM10 concentration overall presented rising tendency from east to west, in which annual average PM10 concentration in northeast district was the minimum, while annual average PM10 concentration in the northwest district was the maximum. In 2000, annual average PM10 concentration in the northeast district was between 0.08 and $0.10 \mathrm{mg} / \mathrm{m}^{3}$, while annual average PM10 concentrations in the north and northwest districts were higher than 0.10 $\mathrm{mg} / \mathrm{m}^{3}$. In 2006, the annual average PM10 concentration was basically lower than $0.08 \mathrm{mg} / \mathrm{m}^{3}$ in the northeast district; between 0.08 and $0.10 \mathrm{mg} / \mathrm{m}^{3}$ in some areas of north district; above $0.10 \mathrm{mg} / \mathrm{m}^{3}$ in most areas of the north district; above $0.10 \mathrm{mg} / \mathrm{m}^{3}$ in the northwest district. In 2013, annual average PM10 concentration was between 0.06 and $0.10 \mathrm{mg} / \mathrm{m}^{3}$ in the northeast district; annual average PM10 concentration was between 0.08 and $0.12 \mathrm{mg} / \mathrm{m}^{3}$ in the north district, in which annual average PM10 concentration in some cities of Shanxi Province was higher and had obvious punctiform distribution. Annual average PM10 concentrations in Gansu, Ningxia and some areas of Inner Mongolia in east area of northwest district were between 0.10 and $0.12 \mathrm{mg} / \mathrm{m}^{3}$, and presented obvious zonal distribution, while annual average PM10 concentration in other regions was between 0.08 and $0.10 \mathrm{mg} / \mathrm{m}^{3}$. Annual average PM10 concentration in the west area of the northwest district was higher than $0.10 \mathrm{mg} / \mathrm{m}^{3}$.

\subsection{The Impact of Wind Velocity on PM10 in China's Northern Cities}

As horizontal movement of the atmosphere, wind is a major characteristic amount reflecting dynamic stability of the atmosphere. As a meteorological parameter closely related to atmospheric pollution, wind plays an important role in the dilution diffusion and three-dimensional transmission of atmospheric pollutants. Generally speaking, larger wind velocity is conductive to PM10 diffusion, and PM10 concentration becomes lower correspondingly. On the contrary, PM10 concentration is higher. The above situation is especially obvious in the northeast and the north districts of China's northern cities. But in the northwest district of China's northern cities (east and west areas of the northwest district), due to the impact of gale weather in the spring and arid ground, gale blows ground dust, making horizontal visibility decline, and even involves a large number of dust into near-earth gas reservoir to induce sandstorm. In this case, PM10 concentration can increase as wind velocity increases. We respectively selected one station in the northeast district, the north district, the east area and the west area of the northwest district in China's northern cities in 2013 to study, and distribution scatter plots between particulate matter concentration and wind velocity in China's northern cities were shown as Fig. (5).

Seen from Fig. (5), PM10 concentration in four cities of northern China in 2013 mainly distributed in interval range that hourly average wind velocity $\leq 8 \mathrm{~m} / \mathrm{s}$. Within the interval range of hourly average wind velocity $\leq 2 \mathrm{~m} / \mathrm{s}$, PM10 concentration distribution was the most concentrated, and there were higher values. According to the situation shown as Fig. (5), correlation between PM10 mass concentration and wind velocity was analyzed (Table $\mathbf{1}$ ).

Seen from Table 1, in China's northern cities, PM10 hourly concentration and average hourly wind velocity presented negative correlation when wind velocity $<6 \mathrm{~m} / \mathrm{s}$. 

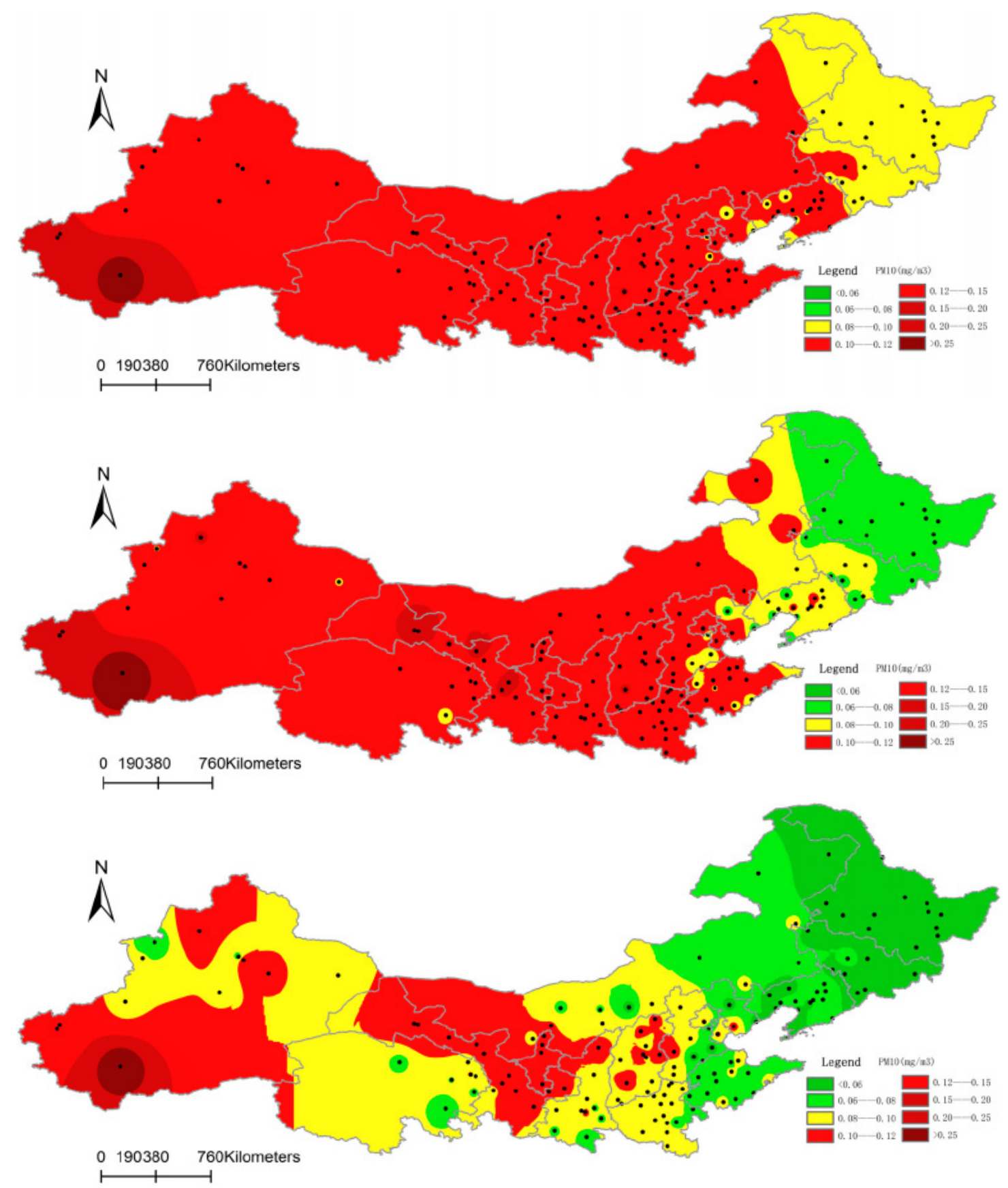

Fig. (4). Spatial distribution pattern of $\mathrm{PM}_{10}$ pollution in China's northern cities in 2000, 2006 and 2013.

That is, the larger the wind velocity, the lower the PM10 concentration. When wind velocity $\geq 6 \mathrm{~m} / \mathrm{s}$, PM10 hourly concentration and average hourly wind velocity presented positive correlation. When wind velocity $\geq 6 \mathrm{~m} / \mathrm{s}$, sand and dust weather occurred in Urumqi and Lanzhou City. Wind velocity increasing became direct reason of sand and dust weather occurrence. At this time, a lot of dust was suspended in the air, presenting the status that particulate matter concentration rose as wind velocity increased. When the wind velocity was $\geq 6 \mathrm{~m} / \mathrm{s}$ and because there was constructions around the monitoring site in Jinan City, gale transported a lot of particulate matters into the air, correlating the PM10 concentration and the wind velocity. As can be seen from the correlation coefficient R2 between particulate matter concen- tration and wind velocity, the impact of wind velocity on PM10 concentration had a certain threshold. In the northwest district of China's northern cities (west and east areas of the northwest district), when the wind velocity is $\leq 2 \mathrm{~m} / \mathrm{s}$, the wind velocity is greater, the pollutant diffusion becomes less. When the wind velocity exceeded $2 \mathrm{~m} / \mathrm{s}$, it was conductive to pollutant diffusion, bringing the dust on the ground surface into air, thereby making negative correlation coefficient decline. In the northeast and north districts, when wind velocity $\leq 1 \mathrm{~m} / \mathrm{s}$, PM10 hourly concentration and average hourly wind velocity had stronger negative correlation, the negative correlation coefficients were -0.597 and -0.401 respectively. As wind velocity increased, its negative correlation was gradually declining. 

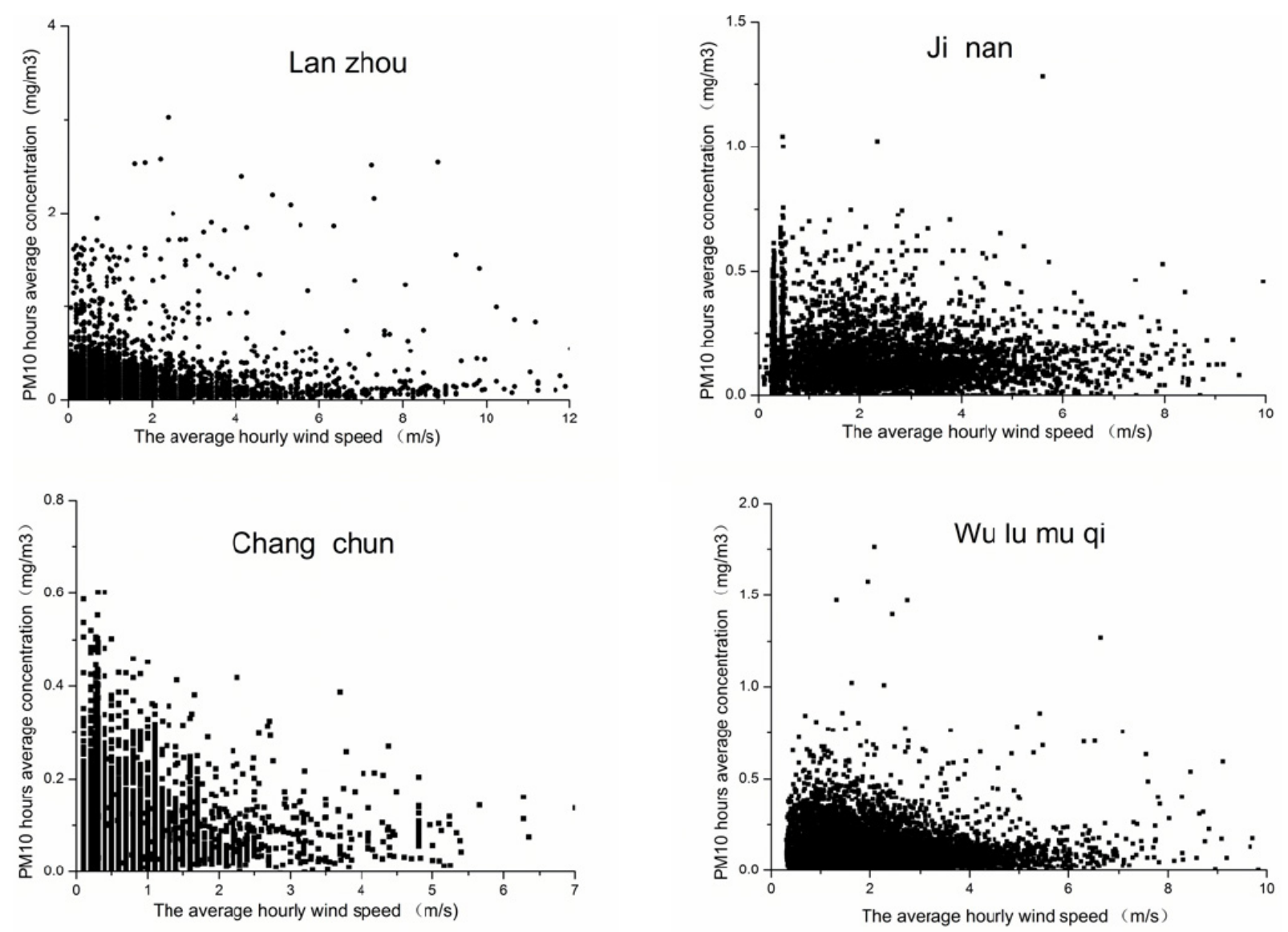

Fig. (5). Distribution scatter plots between particulate matter concentration and wind velocity in China's northern cities in 2013.

Table 1. Correlation coefficients between wind velocities at different ranges and $\mathbf{P M}_{10}$ mass concentration.

\begin{tabular}{|c|c|c|c|c|c|c|c|c|c|c|c|c|c|}
\hline \multirow{2}{*}{ Site name } & \multirow{2}{*}{ Latitude } & \multirow{2}{*}{ Longitude } & \multirow{2}{*}{$\begin{array}{c}\text { Number } \\
\text { of } \\
\text { Samples }\end{array}$} & \multicolumn{10}{|c|}{ Correlation Coefficient Of Concentration And Wind Speed $\left(\mathbf{R}^{2}\right)$ In Different Speed Range } \\
\hline & & & & $\mathbf{R}^{2}$ & Rate & $\mathbf{R}^{2}$ & Rate & $\mathbf{R}^{2}$ & Rate & $\mathbf{R}^{2}$ & Rate & $\mathbf{R}^{2}$ & Rate \\
\hline Wulumuqi & 87.5987 & 43.8156 & 7997 & -0.298 & 0.154 & -0.381 & 0.365 & -0.227 & 0.273 & -0.139 & 0.195 & 0.025 & 0.014 \\
\hline Lanzhou & 103.9100 & 36.0469 & 5458 & -0.399 & 0.567 & -0.451 & 0.219 & -0.207 & 0.087 & -0.212 & 0.090 & 0.0028 & 0.038 \\
\hline Changchun & 125.3047 & 43.8331 & 7078 & -0.597 & 0.881 & -0.436 & 0.128 & -0.233 & 0.018 & -0.251 & 0.005 & 0 & 0 \\
\hline
\end{tabular}

\subsection{The Impact of Temperature on PM10 in China's Northern Cities}

We selected four stations in the northeast district, the north district, the eastern and western areas of northwest district of China's northern cities in 2013 to analyze the relationship between temperature and PM10 concentration in China's northern cities (Fig. 6).

Seen from Fig. (6), temperature differences between daytime and night in Lanzhou in the east area of the northwest district was the most, followed by other three cities. In July and August with higher temperature, particulate matter concentration peak did not appear. Similarly, in January and February with lower temperature, particulate matter concentration peak or decline did not appear. It illustrated that PM10 mass concentration did not have obvious correlation with the temperature, and climate conditions related with temperature did not have significant impact on PM10 distribution in the air, such as sunshine intensity and sunshine time.

\subsection{The Impact of Humidity on PM10 in China's North- ern Cities}

We selected four stations in the northeast district, the north district, the eastern and western areas of the northwest district of China's northern cities in 2013 to analyze the relationship between humidity and PM10 concentration in China's northern cities. With the rising or declining of the relative humidity, the PM10 concentration showed the 

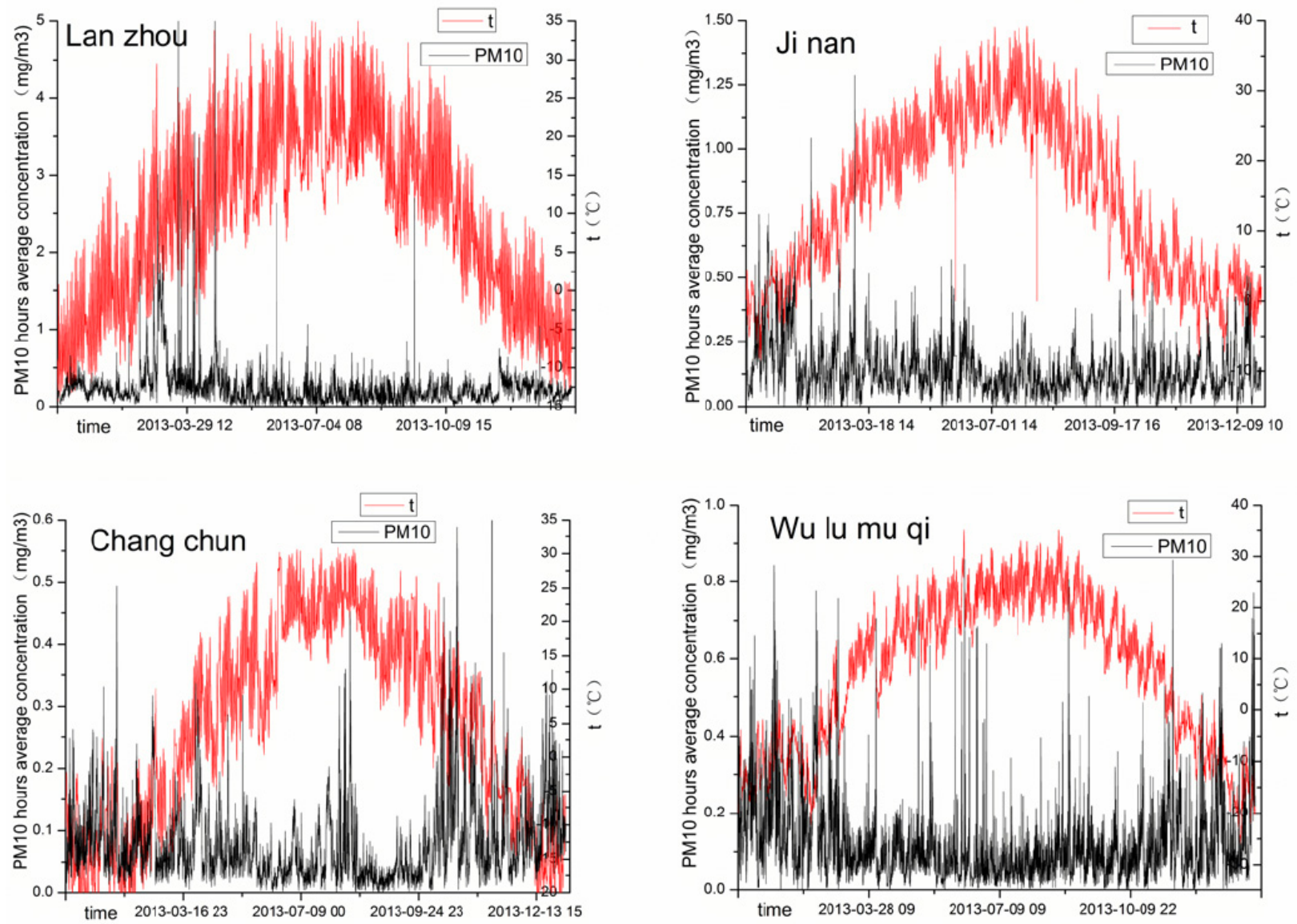

Fig. (6). The relationship between temperature and $\mathrm{PM}_{10}$ concentration in China's northern cities.

change tendency was not necessarily the same. However, in certain humidity range, taking the gravitational settling not occurring as boundary, larger relative humidity was conductive to the formation of particulate matter. In the research about four cities of northern China, it was found that PM10 concentration and relative humidity had different correlation relationships at various stations in different seasons. In the spring, due to the invasion of sand and dust weather, in Urumqi and Lanzhou in the western and eastern areas of the northwest district, correlation coefficients $\mathrm{R}^{2}$ between PM10 concentration and relative humidity were 0.2407 and 0.2365 respectively. In Changchun and Jinan of the northeast and the north districts, $\mathrm{R}^{2}$ were 0.3319 and 0.3256 respectively. In summer and autumn, because that period is dominated by temperate monsoon climate and temperate continental climate in China's northern cities, precipitation mainly occurs during the period, and precipitation can play a cleaning and scouring role on the pollutants in the air, thereby making PM10 concentration decline. Therefore, PM10 concentration and relative humidity did not have obvious positive correlation relationship in these seasons. In winter, China's northern cities are mainly controlled by Siberian high pressure and Mongolia high pressure, and climate condition is relatively stable. Correlation coefficients $\mathrm{R}^{2}$ between PM10 concentration and relative humidity are Lanzhou (0.395 8) > Jinan (0.364 5) > Changchun (0.345 7) > Urumqi (0.304 2). For China's northern cities, relative humidity is an important factor affecting inhalable particulate matter pollution in winter, and high- humidity air is easy to cause more serious particulate matter pollution.

\subsection{The Impact of Atmospheric Pressure on PM10 in China's Northern Cities}

Atmospheric pressure is closely related to atmospheric circulation. When ground is controlled by low pressure, high-pressure air mass all around flows to the center, and ascending airflow is formed at the center. When ground is controlled by high pressure, downdraft appears in center part, hindering upward diffusion of pollutant. Under the control of stable high pressure, atmospheric pollution aggravates, and particulate matter concentration is higher. Seen from Fig. (7), atmospheric pressure in China's northern cities changes little in the whole year, and is basically at dynamic equilibrium status as seasons change. However, $\mathrm{PM}_{10}$ concentration does not present dynamic equilibrium status. It shows that the impact degree of atmospheric pressure on particulate matter concentration in China's northern cities is not of great importance and atmospheric pressure is not a direct factor affecting inhalable particulate matter pollution in China's northern cities.

\section{CONCLUSION}

Due to its special climate type and geographic position distribution, inhalable particulate matter in China's northern cities presented special distribution rule in different seasons in various space environments. 

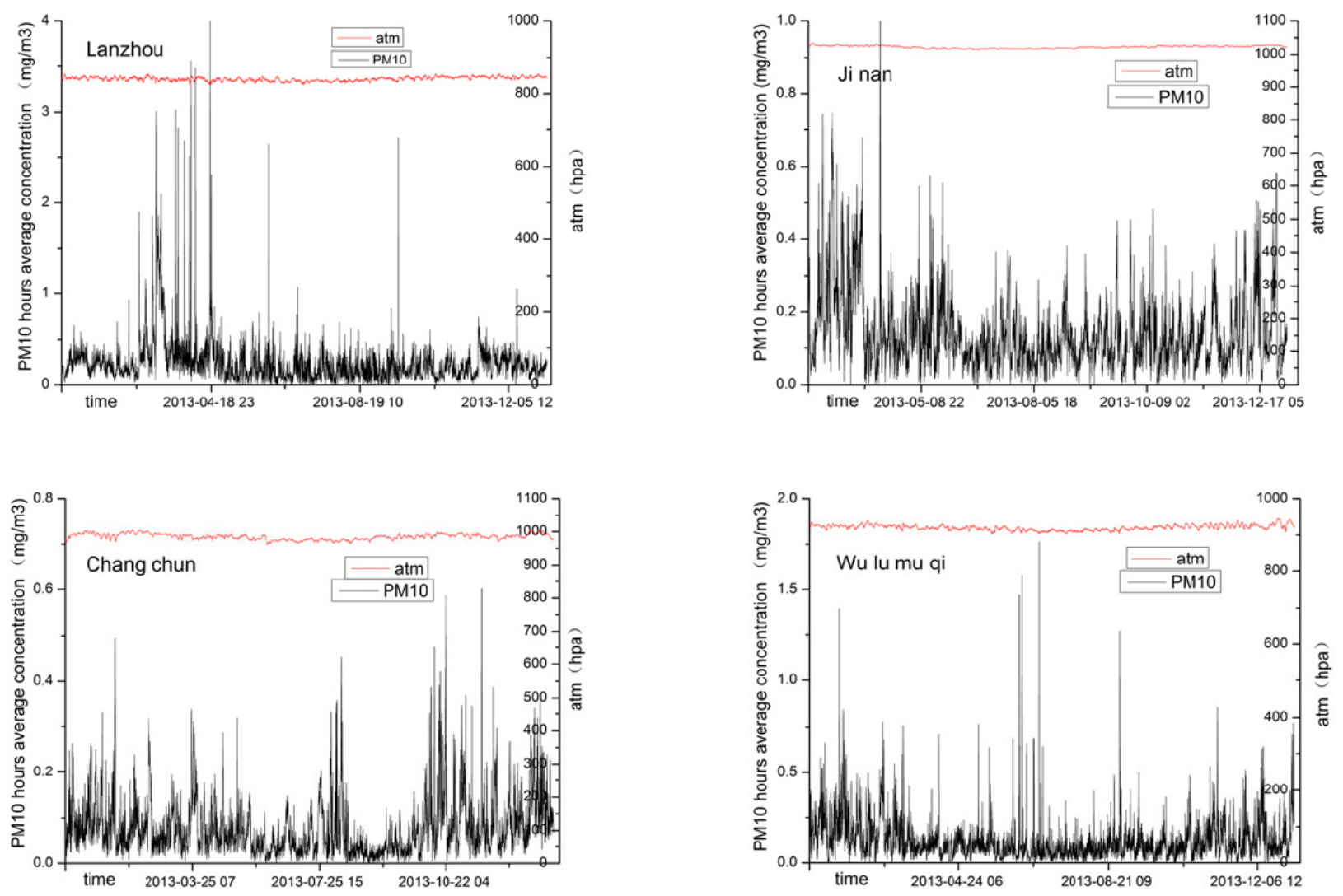

Fig. (7). The relationship between atmospheric pressure and $\mathrm{PM}_{10}$ concentration in China's northern cities.

During 2000-2013, the maximum of inhalable particulate matter concentration in China's northern cities appeared in March, and the second most appeared in December. Monthly average concentrations of particulate matter were relatively lower in summer and autumn. Annual average PM10 concentration presented the tendency of gradually rising from east to west, and the whole tendency of regional distribution for inhalable particulate matter pollution changed from the concentrated contiguous distribution into sporadic zonal and punctiform distribution.

Meteorological parameters had an important impact on inhalable particulate matter concentration in China's northern cities. Wind velocity and humidity were major factors affecting inhalable particulate matter pollution in China's northern cities, while temperatures and atmospheric pressures did not have obvious impact.

\section{CONFLICT OF INTEREST}

The authors confirm that this article content has no conflict of interest.

\section{ACKNOWLEDGEMENTS}

Declared none.

\section{REFERENCES}

[1] A. Baulig, M. Sourdeval, M. Meyer, et al. "Biological effects of atmospheric particles on human bronchial epithelial cells: comparison with diesel exhaust particles," Toxicology in vitro, vol. 17, pp. 567-573, 2003.
[2] H. Kapitza, and D. P. Eppel, "A Case Study in Atmospheric Lead Pollution of North German Coastal Regions," Journal of Applied Meteorology, vol. 39, no.4, pp.563-575, 2000.

[3] Q. Zhang, J. Zhang, and H. Xue, "The challenge of improving visibility in Beijing," Atmos. Chem. Phys. vol.10, no. 3, pp. 6199$6218,2010$.

[4] Z. A. Qian, M. H. Song, and W. Y. Li, "Analyses on distributive variation and forecast of sand-dust storm in recent 50 years in North China," Journal of Desert Research, vol. 22, no.2, pp. 106$111,2002$.

[5] X. M. Wang, X. Ding, X. X. Fu, Q. F. He, S. Y. Wang, F. Bernard, et al., "Aerosol scattering coefficients and major chemical compositions of fine particles observed at a rural site hit the central Pearl River Delta, South China," Journal of Environmental Sciences, vol. 24, no.1, pp. 72-77, 2012.

[6] Y. Zhao, J. Pan, H. Zhang, et al. "Analysis of inhalable particles pollution in the atmosphere in Beijing Area," Research of Environmental Sciences, vol.17, no.1, pp. 67-69, 2004.

[7] X. Li, and H. Cheng, "Influence of Dust WeatheronAir Quality in Lan zhou City," Meteorological an Enviromental Research, vol. 4, no. 11, pp. 52-54, 2013.

[8] B. Wang, M. Shao, S. H. Lu, B. Yuan, Y. Zhao, M. Wang, et al., "Variation of ambient non-methane hydrocarbons in Beijing city in summer 2008," Atmospheric Chemistry and Physics, vol.10, pp. 5911-5923. DOI: 10.5194/acp-10-5911-2010, 2010.

[9] D. Uri, and L. Ilan, "The Influence of Meteorological Conditions and Atmospheric Circulation Types on PM10 and Visibility in Tel Aviv," Journal of Applied Meteorology, vol. 44, no. 5, pp. 606-619, 2005.

[10] L. Juneng, M. T. Latif, F. T. Tangang, et al. "Spatio-temporal characteristics of PM10 concentration across Malaysia," Atmospheric Environment, vol. 43, no.30, pp. 4584-4594, 2009.

[11] L. Juneng, M. T. Latif, and F. Tangang, "Factors influencing the variations of PM10 aerosol dust in Klang Valley, Malaysia during the summer,' Atmospheric Environment, vol.45, no. 26,pp. 4370$4378,2011$.

[12] W. C. Wang, K. S. Chen, S. K. Wang, et al. "Modeling atmospheric PM10 concentrations during severe pollution events in 
southern Taiwan," Atmospheric Research, vol. 92, no. 2, pp. 159$171,2009$.

[13] K. Auana, and X.C. Pan, "Exposure-response functions for health effects of ambient air pollution applicable for China: a Meta analysis," Science of the Total Environment, vol. 329, pp. 3-16, 2004.
[14] R. Zhang, J. Jing, J. Tao, S.C. Hsu, G. Wang, J. Cao, et al., "Chemical characterization and source apportionment of PM2.5 in Beijing: seasonal perspective," Atmos. Chem. Phys. Discuss, vol.13, no.4, 9953-10007, 2013.

Received: June 10,2015

(C) Huibo et al.; Licensee Bentham Open.

This is an open access article licensed under the terms of the Creative Commons Attribution Non-Commercial License (http://creativecommons.org/licenses/by-nc/3.0/) which permits unrestricted, non-commercial use, distribution and reproduction in any medium, provided the work is properly cited. 